\title{
Atuação do bibliotecário no campo da editoração eletrônica de periódicos científicos: um estudo do Portal de Periódicos da UFMA
}

\author{
Librarian activities in the field of electronic publishing of scientific journals: a study of the UFMA \\ Journal Portal
}

\author{
Suênia Oliveira Mendes \\ Doutora em Ciência da Informação \\ Universidade Federal do Maranhão \\ suenia.mendes@ufma.br \\ Luhilda Ribeiro Silveira \\ Mestra em Gestão de Unidades de Informação \\ Universidade Federal do Maranhão \\ luhilda@yahoo.com.br \\ Tatiana Cotrim Serra Freire \\ Especialista em Ciência da Informação \\ Universidade Federal do Maranhão \\ tatiana.cotrim@ufma.br
}

\section{Resumo}

A atuação do bibliotecário no campo da editoração em portais de periódicos eletrônicos foi o objeto deste estudo. A investigação objetivou analisar a presença e atuação deste profissional nas revistas que integram o Portal de Periódicos da Universidade Federal do Maranhão (UFMA). A pesquisa foi descritiva, exploratória e documental que analisou o corpo editorial ( 241 currículos) de 25 revistas do Portal de Periódicos da UFMA. Os resultados apontam para um baixo quantitativo $(4,2 \%)$ de bibliotecários que integram as equipes editoriais das revistas deste Portal. Observa-se que muitas das atividades desenvolvidas neste contexto se relacionam com os conteúdos integrantes da formação do bibliotecário, o que aponta para a importância deste profissional - bibliotecário - atuando no cenário da editoração de periódicos.

\section{Palavras-Chave}

Atuação profissional do bibliotecário. Portal de periódicos eletrônicos. Comunicação científica. Editoração eletrônica.

\begin{abstract}
The role of the librarian in the field of electronic publishing, especially the portals of electronic journals, constituted as the object of this study, which aim to analyze the presence and performance of these professionals in the journals that make up the Federal University of Maranhão (UFMA) Journal Portal. The research was descriptive, exploratory and documentary and analyzed the editorial board (241 resumes) of 25 journals of the UFMA Journal Portal. The results point to a low quantitative number (4.2\%) of librarians who are part of the editorial teams of Portal magazines. Note that many of the activities developed in this context are directly or indirectly related to content that is part of the librarian's education, or that it indicates an important professional importance - librarian - in the execution of the scenario of publishing journals.
\end{abstract}

Keywords

Professional performance of the librarians. Electronic journals portal. Scientific communication. Electronic publishing.

DOI: $10.28998 /$ cirev.2020v7n3f

Este artigo está licenciado sob uma Licença Creative Commons 4.0
Submetido em: $14 / 07 / 2020$

Aceito em: $10 / 12 / 2020$

Publicado em: $31 / 12 / 2020$ 


\section{INTRODUÇÃO}

A diversidade de atuação do bibliotecário tanto social quanto técnica é uma marcante característica apontada na formação profissional (seleção, organização da informação, contato com editores/leitores/autores/usuários entre outras) e a comunicação científica, especialmente os periódicos, compõe um dos cenários de atuação deste profissional. A trajetória dos periódicos científicos, do impresso ao eletrônico, envolve a mudança de suporte ao longo de gerações que reflete o próprio desenvolvimento científico e tecnológico ao longo dos tempos.

Neste sentido, o bibliotecário se envolve na dinâmica social e técnica dos meandros dos avanços impulsionados pelo desenvolvimento tecnológico, especificamente no contexto dos periódicos eletrônicos, que culminou com a expansão da editoração eletrônica e da divulgação informacional que se relacionam com as atividades desenvolvidas por bibliotecários, como normalização, formatação de elementos como paginação, imagens, layout, entre outras. Observa-se que o grande diferencial, neste contexto, é o auxílio dos recursos de softwares específicos para o gerenciamento e execução das atividades da editoração, destacando-se neste cenário o Open Journal System (OJS), um dos mais conhecidos e utilizados softwares de publicação eletrônica para revistas de acesso aberto.

Diante do contexto da editoração eletrônica no OJS o presente trabalho investigou se existem bibliotecários nas equipes das revistas do Portal de Periódicos da Universidade Federal do Maranhão (UFMA), além de identificar quantas e quais são as funções exercidas por esses profissionais no Portal. Assim, a pesquisa objetivou analisar a presença e atuação do bibliotecário no campo da editoração eletrônica nas revistas que integram o Portal de Periódicos da UFMA.

\section{ATIVIDADES DO CAMPO DE ATUAÇÃO DO BIBLIOTECÁRIO QUE SE CORRELACIONAM COM A EDITORAÇÃO DE PERIÓDICOS ELETRÔNICOS NO OJS}

Observa-se que parte das atribuições que compreendem o processo de editoração eletrônica de periódicos se relaciona com as atividades que integram a formação do bibliotecário. Nesta perspectiva Freire, Alauzo e Spudeit (2017, p. 83) identificam esse nicho de atuação como um dos "campos emergentes de atuação do bibliotecário". Sustentando essa afirmação destacam que

O bibliotecário é um profissional que atua com a informação e os processos que a envolvem cabendo administrar e disseminar conteúdos usando avançados métodos e técnicas de difusão independente dos suportes ou formatos que a informação se apresente [...]. (FREIRE; ALAUZO; SPUDEIT, 2017, p. 83).

Nessa perspectiva, compreende-se que as diversas possibilidades relacionadas à gestão da informação, presentes nas diferentes atividades realizadas por bibliotecários, é o grande motor da ação no campo da editoração eletrônica, tendo nessa área os eixos das fontes de informação e da comunicação científica como alguns dos grandes gargalos para a sua contribuição.

"Os bibliotecários e analistas têm um papel respeitável na implantação, gestão e execução de portais, no sentido de orientar e garantir o processo de coleta, organização, disseminação e acesso à informação científica institucional.". (GRANTS; OLIVEIRA, 2013, p. 67). 
Dentre essas atividades, que fazem parte do ciclo formativo do profissional da informação destaca-se: normalização de documentos; Indexação e resumos; Indexação em bases de dados; política editorial; direitos autorais e políticas de acesso aberto, dentre outras.

Além disso, o bibliotecário deve ir além e agregar sempre novos conhecimentos aos adquiridos no curso de graduação por meio de outras demandas, que estão presentes no cenário que envolve a tecnologia. Tais conhecimentos devem ser buscados em outros cursos e campos de conhecimento, à medida que os desafios e/ou dificuldades forem surgindo (MOTA; OLIVEIRA, 2005).

Um destes exemplos, como bem pontuado por Freire, Alauzo e Spudeit, (2017) é a necessidade de dominar ferramentas desenvolvidas para a construção e gestão de uma publicação periódica, como o OJS.

Os bibliotecários em sua formação e atuação desenvolvem competências que vão delineando o seu fazer profissional. O conceito de competência perpassa diferentes estruturas da vida social, e se destaca nas esferas educacional e organizacional, sustentando práticas específicas nestes contextos. A competência no âmbito do trabalho é uma dimensão que integra diversos aspectos do fazer do sujeito em uma organização. $O$ seu estudo abre espaço para considerações sobre interações humanas no bojo das conexões entre saberes e demandas nos processos de trabalho. A própria temática da competência é bastante controversa e diversificada em termos de definições e abrangências teórico-conceituais, permitindo a abordagem do fenômeno sobre diversos aspectos, diversas literaturas e múltiplas possibilidades.

Uma das perspectivas acerca do estudo das competências nos aponta que competência "[...] é a junção de conhecimentos, habilidades e atitudes" (FARIAS; LIMA; SANTOS, 2018, p. 74) caracterizada pela mobilização de saberes conforme mostra o Quadro 1.

Quadro 1-Desdobramento do CHA

\begin{tabular}{|c|c|c|}
\hline Conhecimento & Saber & \\
\hline Habilidade & Saber Fazer & competencıa Iecnica \\
\hline Atitude & Querer Fazer & Competência Comportamental \\
\hline
\end{tabular}

Fonte: Leme (2005, p. 18).

O Quadro 1 desdobra a competência em seus pilares e sua integração por meio do conhecimento, habilidade e atitude. A Competência técnica é "[...] o que o profissional precisa saber para desempenhar sua função, por exemplo, idiomas, sistemas de computação [...]" (LEME, 2005, p. 15) enquanto a comportamental é "[...] o que o profissional precisa demonstrar como seu diferencial competitivo e tem impacto em seus resultados, por exemplo, criatividade, flexibilidade, foco em resultados [...]" (LEME, 2005, p. 15).

O conhecimento é o que se aprende na educação formal (escola, faculdade), no trabalho, na vida e quando utilizado no cotidiano está caracterizada a habilidade. E exercer a habilidade de um conhecimento é o que significa atitude (LEME, 2005). Belluzzo (2017) corrobora com a tríade $\mathrm{CHA}$ da competência (Figura 1).

O Quadro 1 e a Figura 1 mostram o desdobramento do $\mathrm{CHA}=$ Conhecimento + Habilidade + Atitude, que juntos se transformam em competência. O desdobramento do CHA em suas características se relaciona com a competência informacional do bibliotecário. A concepção do CHA vem da corrente norte-americana de estudos sobre competência organizacional que podem ser elencados conforme as características dos bibliotecários na editoração (Figura 2). 
Figura 1 - Formação da competência

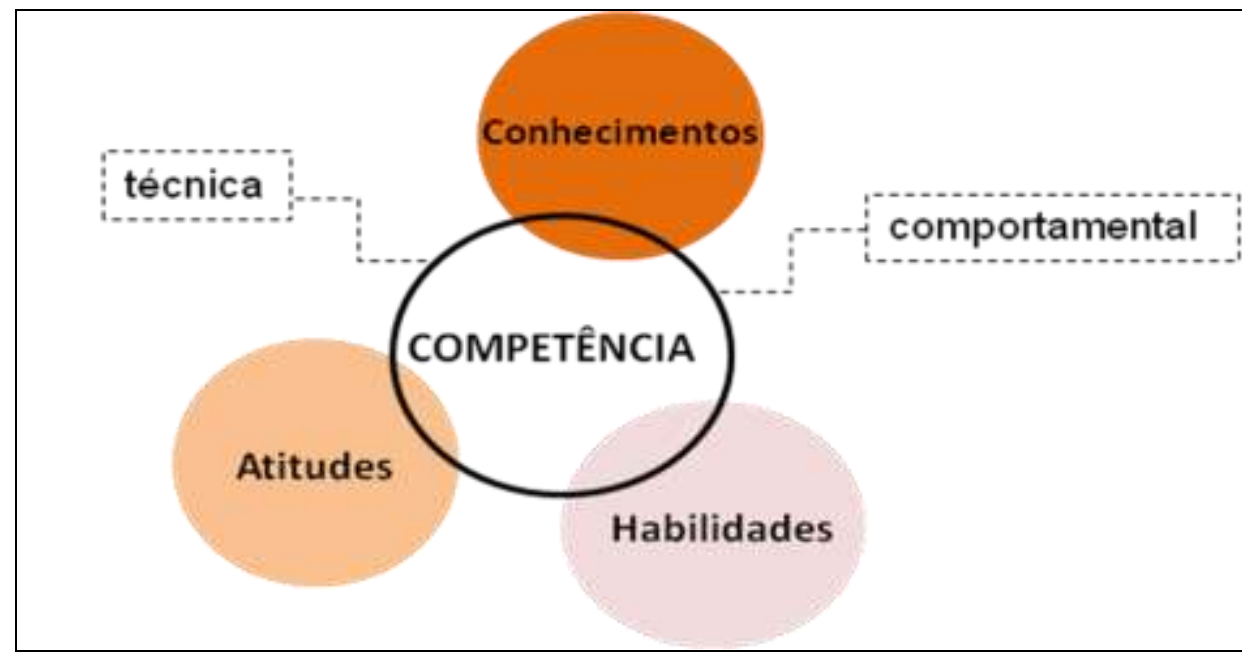

Fonte: Baseado nos desdobramentos do CHA de Leme (2005).

Todas as características elencadas pela Figura 2 mostram que os bibliotecários ainda estão conquistando os espaços de editoração até então restritos à normalização que, com a expansão dos portais de periódicos nas universidades, a editoração digital e a gestão de dados de pesquisa tornaram-se uma atividade gerenciada por bibliotecas universitárias.

Figura 2 - Conhecimentos, habilidades e atitudes para o bibliotecário atuar na editoração
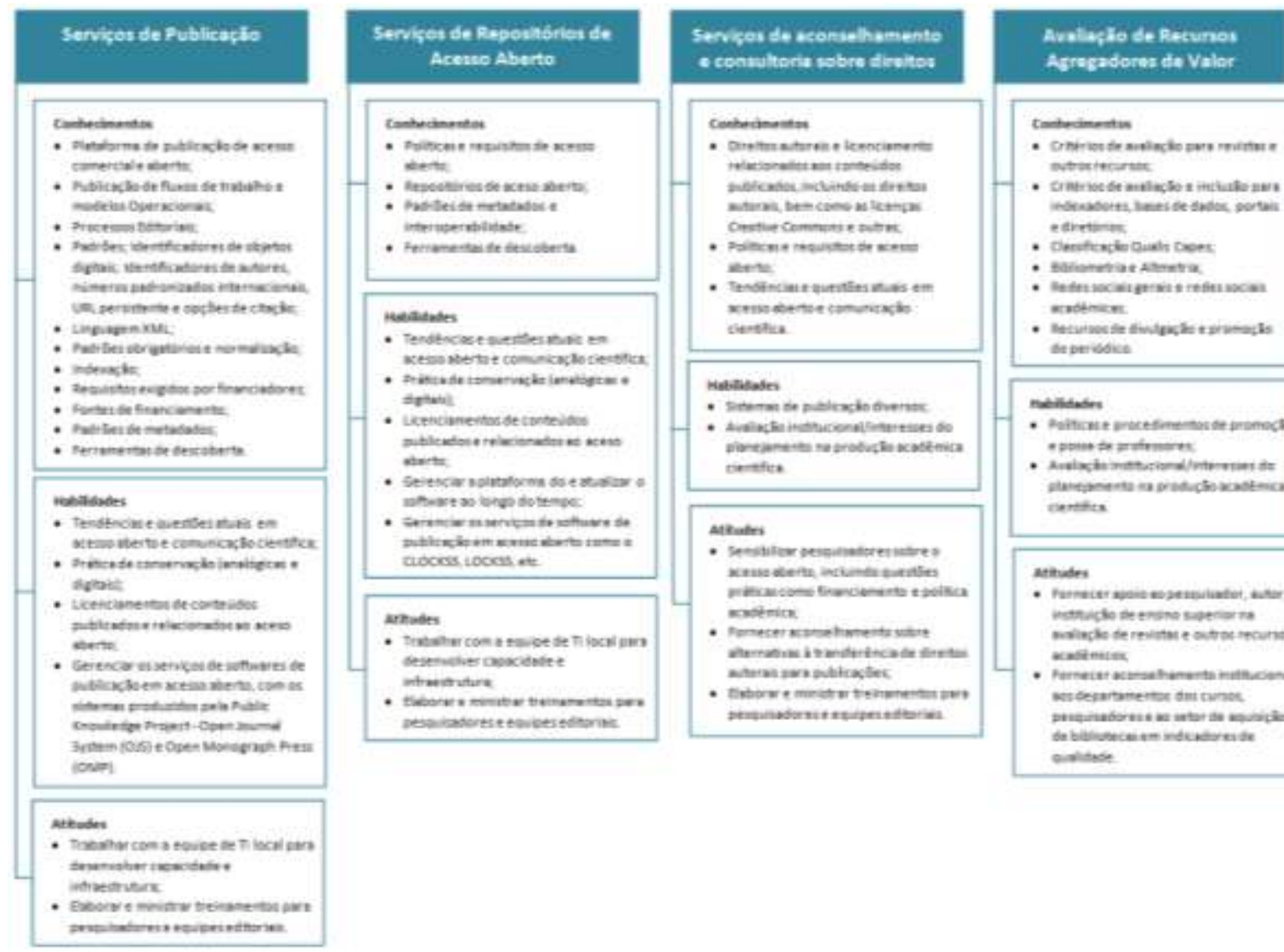

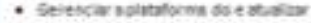

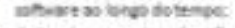

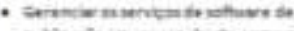

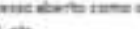
tocess at

armates

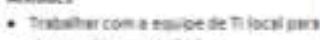
desmelites anocedite

minevature

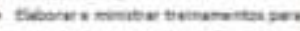

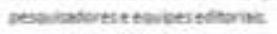

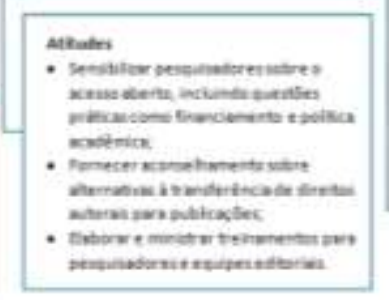

temedeimentio

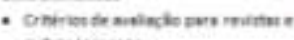

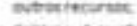

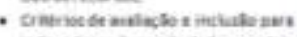

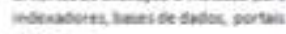
etretimes:

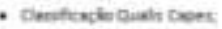

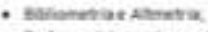

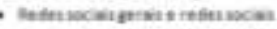

scrotinem:

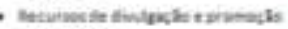
an peribove

\section{neiletes:}

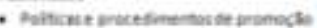
rooms be molveres

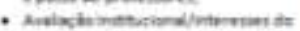

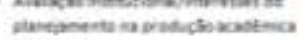
coretes

nethudes

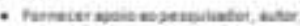

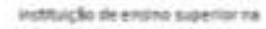

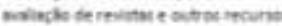
colitming

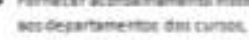

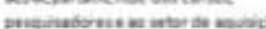

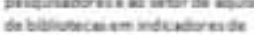
oulitace

Fonte: Farias, Lima e Santos (2018, p. 77). 
A adoção deste novo papel é importante para a biblioteca universitária no cenário de mudanças da comunicação e da editoração científica, pois a coloca como partícipe importante da comunicação científica moderna.

\begin{abstract}
Os serviços de editoração desenvolvidos pelas bibliotecas universitárias têm o potencial de facilitar e ampliar o alcance da comunicação científica das instituições, exercendo influência positiva no trabalho dos diferentes atores deste processo, especialmente nas realidades dos países em desenvolvimento, onde os recursos para a pesquisa são limitados. A possibilidade da editoração digital pela biblioteca universitária se torna, então, ferramenta estratégica no desenvolvimento da ciência nesses países. (SANTILLÁN-ALDANA; MUELLER, 2016, p. 97).
\end{abstract}

Outro enfoque para o estudo da competência sugere uma perspectiva integrativa que envolve o saber mobilizar uma base de conhecimentos em determinado contexto frente às reais situações de trabalho (ZARIFIAN, 2001). Destarte, "A competência é um entendimento prático de situações que se apoia em conhecimentos adquiridos e os transforma na medida em que aumenta a diversidade das situações." (ZARIFIAN, 2001, p. 72).

Na mesma perspectiva, Le Boterf (2003, p. 134) afirma que "Não existe corte total entre o ator e o seu entorno, entre o profissional e sua situação de trabalho. O sujeito é sempre um 'sujeito em situação'.".

Vale a pena destacar que Zarifian (2001) apresenta cinco tipos de competências: competências técnicas; competências sobre processos; competências sobre a organização; competências de serviço; e competências sociais, que estariam em jogo na atuação dos profissionais na organização. Le Boterf (2003) por sua vez apresenta três dimensões que integram a competência: saber, saber-fazer, e saber-ser.

A partir dos pressupostos colocados por esta segunda perspectiva foram elaborados os Quadros 2 e 3 para evidenciar o panorama da abordagem sobre as competências dos bibliotecários no campo da editoração eletrônica.

Quadro 2 - Recursos mobilizados pelos bibliotecários no trabalho em Portais de Periódicos

\begin{tabular}{|c|c|c|}
\hline Competências Técnicas / Saber & $\begin{array}{c}\text { Competência ação no trabalho / } \\
\text { Saber-fazer }\end{array}$ & Competências sociais / Saber-ser \\
\hline $\begin{array}{l}\text { - Conhecimento técnico de Biblio- } \\
\text { teconomia / Catalogação / AACR / } \\
\text { Normas internacionais de descri- } \\
\text { ção } \\
\text { - Comunicação científica } \\
\text { - Movimentos de Open Access / } \\
\text { publicações de código aberto } \\
\text { - Programação / Tecnologia de } \\
\text { Informação e sistemas / Dspace / } \\
\text { TEDE } \\
\text { - Sistema Eletrônico de Editoração } \\
\text { como o OJS } \\
\text { - Normalização/ ABNT / APA / } \\
\text { Vancourver } \\
\text { - Língua inglesa (idioma de parte } \\
\text { das informações dos sistemas } \\
\text { operados) }\end{array}$ & $\begin{array}{l}\text { - Gerenciar as rotinas de trabalho } \\
\text { para inserção das informações em } \\
\text { ambiente digital } \\
\text { - Executar as operações nos sis- } \\
\text { temas para a manutenção do } \\
\text { acervo digital da instituição } \\
\text { - Intermediar as relações entre os } \\
\text { produtores da informação e as } \\
\text { operações nos sistemas de traba- } \\
\text { Iho } \\
\text { - Comunicação na formação de } \\
\text { operadores secundários dos ar- } \\
\text { quivos digitais que compõem o } \\
\text { acervo da instituição } \\
\text { - Acompanhar as mudanças nas } \\
\text { versões dos softwares utilizados }\end{array}$ & $\begin{array}{l}\text { - Saber trabalhar em equipe para } \\
\text { facilitar a interação com interme- } \\
\text { diários do conhecimento } \\
\text { - Identificar-se com o trabalho } \\
\text { ligado à tecnologia da informação } \\
\text { / informática / operação de siste- } \\
\text { mas } \\
\text { - Ter didática para realizar treina- } \\
\text { mentos de operadores secundá- } \\
\text { rios do sistema OJS (editores das } \\
\text { revistas eletrônicas) } \\
\text { - Ser comunicativo para interagir } \\
\text { com os produtores e intermediá- } \\
\text { rios do conhecimento que com- } \\
\text { põem o acervo digital }\end{array}$ \\
\hline
\end{tabular}

Fonte: Elaborado pelas autoras (2019). 
Ainda, tomando como base a perspectiva integrativa da competência, elaborou-se o Quadro 3 para pensar a atuação do bibliotecário no campo da editoração de periódicos eletrônicos que, neste cenário, é entendido com a expressão das competências, relacionandose diretamente com os recursos mobilizados e o contexto de atuação do profissional.

Quadro 3 - Competências relacionadas ao contexto de trabalho

\begin{tabular}{|c|c|c|c|}
\hline \multirow{2}{*}{$\begin{array}{l}\text { Expressão da } \\
\text { competência }\end{array}$} & \multirow{2}{*}{ Recursos mobilizados } & \multicolumn{2}{|c|}{ Contexto } \\
\hline & & Poder agir & Querer agir \\
\hline \multirow{3}{*}{$\begin{array}{l}\text { Gerenciamento da } \\
\text { produção científica } \\
\text { nas publicações perió- } \\
\text { dicas eletrônicas }\end{array}$} & $\begin{array}{l}\text { Saber } \\
\text { - Comunicação científica } \\
\text { - Normas de informação e } \\
\text { documentação científica }\end{array}$ & \multirow{3}{*}{$\begin{array}{l}\text { - Ter produção científica } \\
\text { - Cooperação de diversos } \\
\text { setores } \\
\text { - Funcionamento da rede } \\
\text { de internet } \\
\text { - Funcionamento das } \\
\text { plataformas digitais de } \\
\text { gerenciamento das pu- } \\
\text { blicações } \\
\text { - Disponibilidade de su- } \\
\text { porte tecnológico }\end{array}$} & \multirow{3}{*}{$\begin{array}{l}\text { - Mobilização de recur- } \\
\text { sos em função de um } \\
\text { projeto com significação } \\
\text { para o trabalhador en- } \\
\text { volve aspectos como: } \\
\text { a) situação significativa } \\
\text { construída pelo sujeito } \\
\text { b) autoimagem positiva } \\
\text { c) reconhecimento } \\
\text { d) confiança dos pares } \\
\text { e) retorno financeiro e } \\
\text { etc. }\end{array}$} \\
\hline & $\begin{array}{l}\text { Saber-fazer } \\
\text { - Operar o sistema OJS } \\
\text { - Acompanhar as atualiza- } \\
\text { ções do software utilizado } \\
\text { - Trabalhar com distintas } \\
\text { normas de informação e } \\
\text { documentação científica }\end{array}$ & & \\
\hline & $\begin{array}{l}\text { Saber-ser } \\
\text { - Comunicação } \\
\text { - Minuciosidade } \\
\text { - Didática }\end{array}$ & & \\
\hline
\end{tabular}

Fonte: Elaborado pelas autoras (2019).

Embora a discussão acerca das diferentes perspectivas do estudo da competência seja de grande relevância, aqui não se constitui como foco de análise. Neste trabalho, a apresentação de múltiplos entendimentos sobre competência apresenta-se como uma possibilidade para ampliar a percepção sobre a existência das diferentes dimensões que integram a compreensão do tema, abrindo caminhos para que se possa refletir sobre a diversidade da temática. Em todo caso, o destaque aqui recai sobre a figura do bibliotecário e sua atuação profissional, colocando suas competências (sejam estas entendidas sob esta ou aquela perspectiva) a serviço da editoração eletrônica.

A biblioteca acadêmica e o bibliotecário são parceiros institucionais para a comunicação científica, que tem um impacto na aprendizagem e proporciona novas oportunidades para as bibliotecas acadêmicas transformarem a maneira como se envolvem com a aprendizagem, o ensino e a pesquisa nas universidades. Empreende-se, desta forma, a integração entre as equipes multidisciplinares dos periódicos para criação, gestão e organização do conteúdo disponibilizado (FACHIN; HILLESHEIM, 2006; LLEWELLYN, 2019).

\section{PROCEDIMENTOS METODOLÓGICOS}

A pesquisa foi do tipo descritiva, exploratória e documental visando contribuir com informações para ampliar a percepção do campo de atuação do bibliotecário voltado para a editoração eletrônica.

O procedimento adotado foi identificar a presença e função do bibliotecário dentro do corpo editorial de cada uma das 25 revistas presentes no Portal de Periódicos da UFMA. Desta forma, foram consultados, em agosto de 2019 , os sites de todas as 25 revistas do Por- 
tal e coletados os dados sobre a atuação do bibliotecário na seção "Sobre" e "Equipe" das revistas investigadas.

Os dados sobre a formação da equipe editorial foram coletados nos 241 currículos disponibilizados na própria revista que o pesquisador é integrante do corpo editorial. Os dados coletados e os resultados são mostrados abaixo.

\section{RESULTADOS}

Os portais de periódicos científicos proporcionam "[...] mais legitimidade, confiabilidade e segurança nos processos editoriais, de modo a aumentar a visibilidade, uso e reconhecimento dos periódicos eletrônicos [...]" (SANTA ANNA, 2018).

Os portais de periódicos no Brasil tiveram a versão do OJS customizada e traduzida pelo Instituto Brasileiro de Informação em Ciência e Tecnologia (IBICT), em 2003. O OJS é um "[...] software de gerenciamento e publicação de revistas eletrônicas desenvolvido pelo Public Knowledge Project (PKP), da University of British Columbia." (IBICT, 2019, p. 1). O Portal de Periódicos da UFMA existe desde 2010 com as publicações disponibilizadas em acesso aberto ao conteúdo dos periódicos por meio do sistema OJS.

Os dados coletados nas 25 revistas sobre a quantidade de bibliotecários e bibliotecárias são mostrados na Tabela 1.

Tabela 1 - Quantidade de bibliotecário(a)s das revistas do Portal de Periódicos da UFMA

\begin{tabular}{cccc}
\hline Revistas & $\begin{array}{c}\text { Quantidade de profissional do } \\
\text { corpo editorial }\end{array}$ & \multicolumn{2}{c}{$\begin{array}{c}\text { Quantidade de bibliotecários e } \\
\text { bibliotecárias }\end{array}$} \\
\hline $\boldsymbol{f}(\boldsymbol{x})$ & $\boldsymbol{f}(\boldsymbol{x})$ & $\boldsymbol{f}(\boldsymbol{x})$ & $\boldsymbol{f}(\%)$ \\
$\mathbf{2 5}$ & 241 & 10 & 4,2 \\
& & $35^{*}$ & 14,5 \\
\hline
\end{tabular}

(*) Inclusão de 25 bibliotecários que compõem um título do Portal de Periódicos da UFMA.

Fonte: Dados da pesquisa (2019).

A Tabela 1 mostra que das 25 revistas existentes no Portal de Periódicos da UFMA existe a presença de 241 profissionais, com formações diversas, exercendo funções no corpo editorial das revistas, como: editore(a)s, avaliadores, criação de layout entre outras. Os bibliotecários/bibliotecárias totalizaram em 10 o que corresponde a 4,2\% dos profissionais que compõem o corpo editorial exercendo as funções de: revisor de normalização, editor da revista e colaborador. Chama-se atenção que existe uma bibliotecária exercendo várias funções em diversas revistas.

Outro destaque é que existe uma revista do Portal que é da Ciência da Informação e áreas afins o que provoca um outlier nos resultados. "Um outlier é uma observação que se desvia tanto das outras observações que suscita suspeitas de que foi gerada por um mecanismo diferente." (AGGARWAL, 2015, p. 237).

A revista da Ciência da Informação e áreas afins que possui o outlier tem corpo editorial todo composto por bibliotecários/bibliotecárias o que do total de 10 ficam 35 bibliotecários/bibliotecárias como resultado do estudo. Ou seja, os dados (Tabela 1) mostram que o processo editorial das revistas da UFMA possui pouca inserção do profissional bibliotecário/bibliotecária mesmo considerando o corpo editorial da revista da Ciência da Informação e áreas afins (14,5\%). 
Contrário aos achados da presente investigação foi o que Manzato (2019) encontrou em sua pesquisa quando identificou as atividades desenvolvidas pelo bibliotecário no Periódico Conexões: Educação Física, Esporte e Saúde. As atividades identificadas e desenvolvidas por bibliotecários foram, conforme Manzato (2019): apoio técnico e administrativo; assessoria aos autores e pareceristas; assessoria técnica; divulgação ao público; editoria executiva; elaboração de relatórios; elaboração de análises métricas; gerenciamento de redes sociais; prestação de contas; assistência editorial; diagramação; edição de texto; gerenciamento do fluxo editorial; produção editorial; secretaria de edições; elaboração de ficha catalográfica; indexação; normalização técnica; marcação Extensible Markup Language (XML); manutenção do site do periódico; e organização e gerenciamento de dados virtuais.

Verifica-se que as atividades descritas acima, como apoio técnico e administrativo; assessoria aos autores e pareceristas são desenvolvidos pelos bibliotecários Gestores do Portal de Periódicos da UFMA. A manutenção do site do Portal é feita pela equipe da Superintendência de Tecnologia da Informação (STI) da UFMA. Outro ponto é que com a individualização dos artigos científicos como unidades de informação a diagramação se faz pela normalização dos artigos editorados no OJS.

O OJS é um sistema com campos pré-estabelecidos e que, apesar da versão 3, em HyperText Markup Language (HTML), sua customização é algo que precisa de um conhecimento em linguagem de programação. Provavelmente, esta é uma nova competência do bibliotecário.

Santana e Francelin (2016) identificaram as atividades exercidas por bibliotecários em 37 periódicos do Portal de Revistas da USP e os autores elaboraram as configurações de uma equipe editorial de periódico científico (Figura 3) e o agrupamento das atividades por campo de atuação profissional.

Figura 3 - Configuração de uma equipe editorial de periódico científico

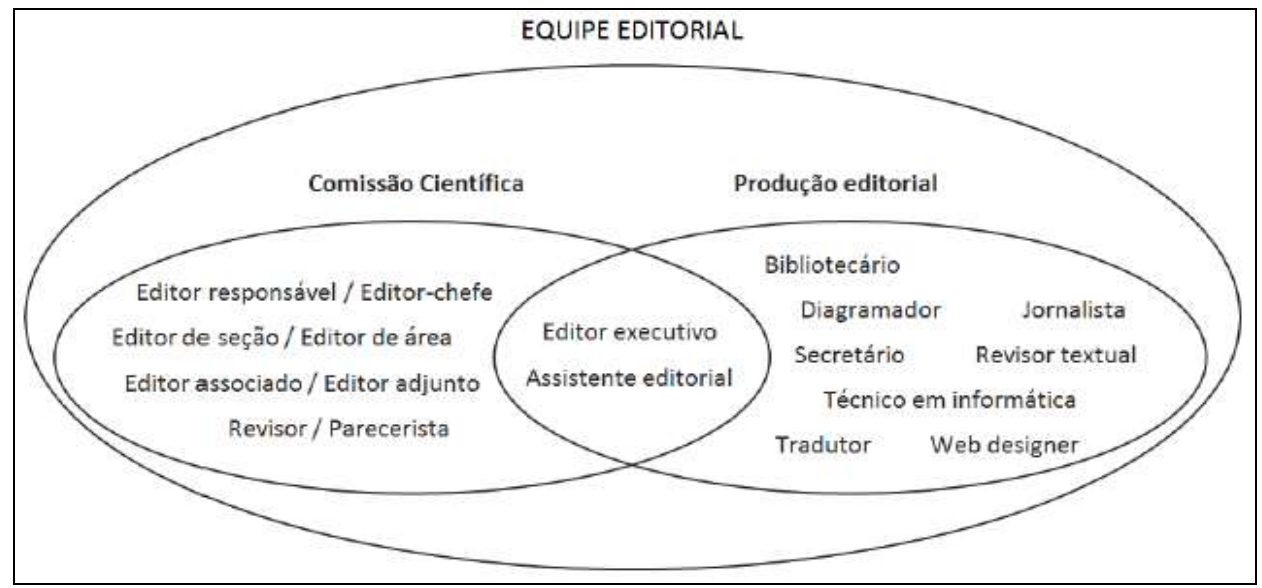

Fonte: Santana e Francelin (2016, p. 10).

Em análise ao que Santana e Francelin (2016) elencaram na Figura 3 e correlacionado com o Portal de Periódicos da UFMA, verifica-se que a equipe editorial está identificada nas funções da produção editorial. Os autores identificaram que as atividades da editoração podem ser agrupadas em quatro grandes áreas profissionais: Administração, Biblioteconomia, Editoração e Tecnologia da Informação. Assim, o agrupamento das atividades de cada área corresponde à:

a) Administração: apoio técnico e administrativo; assessoria aos autores e pareceristas; assessoria técnica; desenvolvimento de projetos; divulgação ao público; edi- 
toria executiva; elaboração de análises métricas; gerenciamento de redes sociais; e prestação de contas;

b) Editoração: assistência editorial; diagramação; edição de texto; gerenciamento do fluxo editorial; produção editorial; revisão textual; e secretaria de edições;

c) Biblioteconomia: elaboração de ficha catalográfica; indexação; e normalização;

d) Tecnologia da informação: marcação XML; manutenção do site do periódico; organização e gerenciamento de bases de dados virtuais.

Os autores Santana e Francelin (2016) especificaram a atuação da área da Biblioteconomia que focada ao profissional bibliotecário(a) abrange todas as outras áreas em algum aspecto, como assessoria técnica, diagramação e marcação XML.

Sobre o Portal de Periódicos da UFMA, que é gerenciado pela Diretoria Integrada de Bibliotecas (DIB) da UFMA, o mesmo oferece serviços de: assistência inicial aos editores das revistas recém-hospedadas, assessoria sobre práticas de publicação, atribuição de Digital Object Identifier (DOI), revisão do preenchimento de metadados dos artigos, registro de International Standard Serial Number (ISSN), assistência de editoração de periódicos, preservação digital por meio do Lots of Copies Keep Stuff Safel (LOCKSS) da Rede Cariniana, treinamento de editores e usuários em geral, assessoria em relação a licenças creative commons, recomendações sobre normalização, suporte técnico, treinamento e recomendação de indexação em bases de dados que, conforme Marra e Weitzel (2015, p.7), são fazeres que atendem "[...] aos interesses da própria universidade ao organizar, disseminar e preservar a informação."

Os portais sendo coordenados por bibliotecas universitárias "[...] atendem aos interesses da própria universidade ao organizar, disseminar e preservar a informação [... e o] OJS oferece um serviço de hospedagem econômica, eficiente e profissional." (MARRA; WEITZEL, 2015, p. 4-7). E ao perfil profissional do bibliotecário e da bibliotecária na editoração eletrônica de revistas científicas que fundamenta sua atuação na liberdade da investigação científica.

\section{CONCLUSÃO}

Ao analisar a presença e atuação de bibliotecários e bibliotecárias nas equipes editoriais dos periódicos do Portal da UFMA foi identificada a escassez deste profissional tanto em quantidade (10) quanto em atividades desenvolvidas (revisor de normalização, editor da revista e colaborador).

Os resultados encontrados mostram que os fazeres dos bibliotecários descritos pela literatura sobre competência são executados, principalmente, pelas três bibliotecárias que integram a Equipe de Gestão do Portal de Periódicos da UFMA, ou seja, a pouca presença de bibliotecários e bibliotecárias como integrantes das equipes das revistas do Portal $(4,2 \%)$ acarreta uma maior demanda às bibliotecárias gestoras do Portal.

Conclui-se e sugere-se que as revistas do Portal de Periódicos da UFMA, do Brasil e do Mundo tenham, pelo menos, um bibliotecário por revista incentivando critérios de elegibilidade internacional da publicação científica periódica, como ISSN, normalização, indexação em bases de dados e padrões do acesso aberto por meio do fluxo informacional na dinâmica da publicação científica desde o recebimento do manuscrito até a publicação do documento. 


\section{REFERÊNCIAS}

AGGARWAL, C. C. Outlier analysis. In: AGGARWAL, Chara C. Data mining. United Kingdom: Springer Nature, 2015.p. 237-263.

BELLUZZO, R. C. B. O estado da arte da competência em informação (Colnfo) no Brasil: das reflexões iniciais à apresentação e descrição de indicadores de análise. Revista Brasileira de Biblioteconomia e Documentação. São Paulo, v. 13, n. especial, p. 47-76, jan./jul. 2017. Disponível em: https://rbbd.febab.org.br/rbbd/article/view/648/570. Acesso em: 20 jan. 2020.

FACHIN, G. R. B.; HILLESHEIM, A. I. A. Periódico científico: padronização e organização. Florianópolis: EdUFSC, 2006.

FARIAS, M. G. G.; LIMA, J. S.; SANTOS, F. E. P. Bibliotecário e editoração: mercado e competências necessárias. Informação \& Sociedade: Estudos, João Pessoa, v. 28, n. 2, p. 63-81, 2018. Disponível em: https://periodicos.ufpb.br/ojs2/index.php/ies/article/view/38682. Acesso em: 15 jan. 2020.

FREIRE, F. S.; ALAUZO, J. L. C.; SPUDEIT, D. F. A. Competências e campos emergentes para atuação de bibliotecários. RACIn: Revista Analisando em Ciência da Informação, João Pessoa, v. 5, n. 1, p. 81-102, jan.-jun. 2017. Disponível em:

http://racin.arquivologiauepb.com.br/edicoes/v5 n1/racin v5 n1 artigo05.pdf. Acesso em 10 jun. 2019.

GRANTS, A. F. L.; OLIVEIRA, A. P. Visibilidade, credibilidade e padronização: o modelo de gestão do Portal de Periódicos UFSC. In: AMBONI, Narcisa de Fátima (Org.). Gestão de bibliotecas universitárias: experiências e projetos da UFSC. Florianópolis: [s.n.], 2013. Disponível em:

https://repositorio.ufsc.br/bitstream/handle/123456789/99534/gestaobibliotecasuniversita rias bu ufsc.pdf?sequence=1\&isAllowed=y. Acesso em: 12 dez. 2019.

IBICT. Sistema eletrônico de editoração de revistas (SEER). 2019. Disponível em: http://www.ibict.br/tecnologias-para-informacao/seer. Acesso em: 10 jun. 2019.

LE BOTERF, G. Desenvolvendo a competência dos profissionais. 3.ed. Porto Alegre: Artmed, 2003.

LEME, R. Aplicação prática de gestão de pessoas por competências: mapeamento, treinamento, seleção, avaliação e mensuração de resultados de treinamento. 2. ed. Rio de Janeiro: Qualitymark, 2005.

LLEWELLYN, A. Innovations in learning and teaching in academic libraries: a literature review. New Review of Academic Librarianship, v. 25, n. 2-4, p. 129-149, 2019.

MANZATO, A. O papel do bibliotecário na editoração de periódicos científicos: um estudo de caso. In: ENCONTRO NACIONAL DE PORTAIS DE PERIÓDICOS, 2., 2019, São Paulo. Anais [...]. São Paulo: ENAPP, 2019. Disponível em: 
https://econtents.bc.unicamp.br/eventos/index.php/enapp/article/view/1545/1630. Acesso em: 19 jan. 2020.

MARRA, P. S. C.; WEITZEL, S. R. Portais de periódicos de acesso aberto nas universidades brasileiras: a utilização do open journal systems. In: ENCONTRO NACIONAL DE PESQUISA EM CIÊNCIA DA INFORMAÇÃO, 16., 2015, João Pessoa. Anais [...]. Paraíba: ENANCIB, 2015. Disponível em:

http://www.ufpb.br/evento/index.php/enancib2015/enancib2015/paper/viewFile/3134/11 46. Acesso em: 12 fev. 2020.

MOTA, F. R. L.; OLIVEIRA, M. Formação e atuação profissional. In: OLIVEIRA, M. (Coord.). Ciência da Informação e Biblioteconomia: novos conteúdos e espaços de atuação. Belo Horizonte: UFMG, 2005.

SANTANA, S. A.; FRANCELIN, M. Mr. O bibliotecário e a editoração de periódico científico. Revista Brasileira de Biblioteconomia e Documentação, São Paulo, v. 12, n. 1, p. 2-26, jan./jun. 2016. Disponível em: https://rbbd.febab.org.br/rbbd/article/view/543. Acesso em: 01 jul. 2019.

SANTA ANNA, J. Mapeamento sistemático na base de dados em Ciência da Informação: periódicos científicos em discussão. Brazilian Journal of Information Science: research trends, v. 12, n. 1, maio 2018. Disponível em:

http://www2.marilia.unesp.br/revistas/index.php/bjis/article/view/7296. Acesso em: 02 jul. 2019.

SANTILLÁN-ALDANA, J.; MUELLER, S. P. M. Serviços de editoração desenvolvidos por bibliotecas universitárias. Perspectivas em Ciência da Informação, Belo Horizonte, v. 21, n. 2, p.84-99, 2016. Disponível em: http://www.scielo.br/pdf/pci/v21n2/1413-9936-pci-21-0200084.pdf. Acesso em: 27 jan. 2020.

ZARIFIAN, P. Objetivo competência: por uma nova lógica. São Paulo: Atlas, 2001. 